\title{
Comparison of commonly used extraction methods for ergosterol in soil samples
}

\author{
Orracha Sae-Tun ${ }^{1 *}$, Rizki Maftukhah ${ }^{1,2}{ }^{1}$, Christoph Noller ${ }^{1}$, Vivian I. Remlinger ${ }^{1}$, Victoria Meyer-Laker ${ }^{1}$, \\ Anders C. T. Sørensen ${ }^{1}$, Dunja Sustic ${ }^{1}$,Sebastian I. Socianu ${ }^{1}$, Luca G. Bernardini ${ }^{3}$, Axel Mentler ${ }^{1}$, \\ and Katharina M. Keiblinger ${ }^{1}$ \\ ${ }^{1}$ Department of Forest and Soil Sciences, University of Natural Resources and Life Sciences, Institute of Soil Research, Vienna, Austria \\ ${ }^{2}$ Department of Agricultural and Biosystem Engineering, Faculty of Agricultural Technology, Universitas Gadjah Mada, \\ Yogyakarta, Indonesia \\ ${ }^{3}$ Department of Crop Sciences, Institute of Agronomy, University of Natural Resources and Life Sciences, Tulln an der Donau, Austria
}

Received June 26, 2020; accepted September 8, 2020

\begin{abstract}
A b stract. Concerning the contribution of fungi to soil carbon sequestration, various methods have been used to extract ergosterol from soil samples. This study aims to explore the extraction ability and applicability of commonly used methods to extract ergosterol from two contrasting soils. An agricultural soil (chernozem) and a forest soil (podzol) were extracted with different types of cell lysis such as alkaline, glass bead, and ultrasonication methods in association with simple shaking. The ergosterol concentration was measured by high pressure liquid chromatography. Regardless of the method applied, ergosterol yield was higher in podzol than in chernozem. Alkaline extraction resulted in the highest ergosterol concentrations for both soils and miniaturized glass bead extraction produced comparable results in the case of chernozem. In terms of applicability, the non-alkaline methods were simpler to conduct and less demanding of labour, chemical use and glassware and more flexible in terms of the equipment used for mechanical disruption. Despite the limit of the two soil types in the present study, only the simple shaking method was revealed to be dependent on soil type. Based on our results, we recommend the miniaturized glass bead method for agricultural soils, low in organic matter for high throughput. However, not all of the methods described allow for the proper separation of coextracted organic substances from organic-rich soil.

Keywords: soil, alkaline extraction, ergosterol extraction, glass bead beating, ultrasonication extraction
\end{abstract}

*Corresponding author e-mail: orrachs@students.boku.ac.at

\section{INTRODUCTION}

Ergosterol, (22E)-Ergosta-5,7,22-trien-3 $\beta$-ol $\left(\mathrm{C}_{28} \mathrm{H}_{44} \mathrm{O}\right)$, is a lipid found in the cell membranes of most fungi and some microalgae (Wallander et al., 2013). It is widely used as a biomarker to estimate fungal biomass in soil. Hence, the quantity of ergosterol in soil can refer to the contribution of fungi to soil organic matter content and subsequently soil organic carbon. However, this data requires careful consideration due to the turnover period of ergosterol in soil after cell death (Young et al., 2006; Zhao et al., 2005) and the lack of ergosterol in the cell membranes of e.g. arbuscular mycorrhiza (van Groenigen et al., 2010) and some Zygomycota (Strickland and Rousk, 2010). Due to the complexity of organic substances in soil and the composition of the fungal cell membrane, the extraction of ergosterol from soil samples is a crucial step for the determination of its amount in the soil.

Various methods are known to successfully extract ergosterol from soil samples followed by quantification using high-pressure liquid chromatography (HPLC) or gas chromatography (GC) (Beni et al., 2014; Joergensen and Wichern, 2008). Soil scientists are attempting to improve

(C) 2020 Institute of Agrophysics, Polish Academy of Sciences 
the extraction methods to save money and time and reduce the use of hazardous chemicals by applying physical disruption and omitting or accelerating the saponification step.

Together with the cell physical disruption, pure ethanol, pure methanol or a methanol-ethanol mixture are used to extract ergosterol from the soil samples without the use of an alkaline solution (Feeney et al., 2006; Joergensen and Wichern, 2008). Some options for physical disruption such as bead-beating, shaking and ultrasonication with less use of hazardous chemicals produce the advantageous characteristics of non-alkaline extractions over alkaline extractions. Apart from that, the process of non-alkaline extraction is also simple due to the omission of the saponification step as well as liquid-liquid phase separation. Therefore, nonalkaline extraction can only extract free ergosterol unlike alkaline extraction (Eash et al., 1996; Seitz et al., 1977).

The use of alkaline solution e.g. methanolic potassium hydroxide $(\mathrm{KOH})$ for saponification targets the liberated esterified ergosterol from fungal cells. Homogenization by ultrasonication and saponification under heating conditions can accelerate the alkaline extraction process (Bååth and Anderson, 2003). After saponification, further steps, including phase separation, purification and derivatization are implemented before quantification by HPLC or GC (Joergensen and Wichern, 2008; Turgay and Nonaka, 2002).

Although non-alkaline extractions cannot liberate esterified ergosterol, ergosterol yields from both non-alkaline and alkaline methods may be comparable (Joergensen and Wichern, 2008). No final explanation has been reached to explain those findings due to the present limits of knowledge concerning the nature of ergosterol in soil fungi (Ruzicka et al., 2000). It has been suggested that saponification during alkaline extraction could possibly result in the decay of some pre-existing free ergosterol (Djajakirana et al., 1996).

When exposed to ultraviolet (UV)-light, the photochemical reaction of ergosterol causes pro-vitamin D creation; however, low energy laboratory light conditions are not sufficient to trigger this reaction (Newell et al., 1988). The stability of the extracted ergosterol could be preserved by storing it in the dark at $4^{\circ} \mathrm{C}$ for up to 3 days prior to quantitative determination (Beni et al., 2014). In ecological studies the heating effect on ergosterol yield and stability from complex samples such as soil is poorly understood. Verma et al. (2002) suggested an optimal heating period at $85^{\circ} \mathrm{C}$ for $30 \mathrm{~min}$ could enhance both the opening of the fungal cell and the release of esterified ergosterol bound to other solid substances during saponification; however, longer heating periods could potentially break down the ergosterol.

The purpose of this study was to implement and compare commonly used extraction methods for the fungal biomarker, ergosterol, from two different soils. Four methods for cell lysis were explored in detail: (i) alkaline extraction, (ii) glass bead, (iii) ultrasonication, and (iv) simple shaking methods. All of the methods were used to extract ergosterol from distinct soils comprising agricultural and forest soils to determine their extraction yields and applicability. We expect that all of the methods used will show a higher fungal content in the forest soil than in the agricultural soil with their consistent extraction ability. In addition to ergosterol yield, it is proposed that the co-extraction of organic compounds is more critical for forest soil where organic matter is rich. This may result in more pronounced differences of applicability among the methods.

\section{MATERIALS AND METHODS}

Topsoils $(0-10 \mathrm{~cm}$ depth $)$ from forest and agricultural lands were studied. An acidic podzol with a silty loam texture was collected from a spruce-fir forest in the Wienerwald, Dürrwien, Austria. An alkaline chernozem with a sandy loam texture was sampled from the Marchfeld in Lower Austria. More details concerning the study site of the chernozem were described in Schomakers et al. (2015). The podzol, as a forest soil, was rich in organic matter of $21.4 \%$ (Table 1) while the agricultural chernozem had a low organic content of $1.17 \%$. Prior to extraction, the soil samples were sieved with a $2 \mathrm{~mm}$ size sieve and air-dried.

Due to the extensive use of the alkaline extraction method in soil study (Beni et al., 2014; de Ridder-Duine et al., 2006), it was selected as a reference method in our study. The alkaline extraction method used in our study followed the procedure from Bååth (2001) with a soil:solvent ratio of 1:5 (weight to volume ratio, w/v). Details concerning the extraction are provided in Appendix A.

The method of ergosterol extraction with glass beads was modified from Gong et al. (2001). The procedure was conducted using two different scales (normal and miniaturized), while the soil:solvent ratio was maintained at 1:5 $(\mathrm{w} / \mathrm{v})$. Soil samples of two different weights, 2 and $0.16 \mathrm{~g}$ were extracted with methanol $(\mathrm{MeOH})$ for the normal-scale and miniaturized extractions, respectively. The details of the extractions are included in Appendix A.

The utrasonication method utilized power from ultrasonic waves to physically disrupt fungal cells in non-alkaline solvent (Ruzicka et al., 1995). A soil sample of $2 \mathrm{~g}$ was

Table 1. Soil characteristics of chernozem and podzol

\begin{tabular}{lcc}
\hline Soil & Chernozem & Podzol \\
\hline Land use & Agricultural land & Spruce-fir forest \\
\hline Soil texture & Silty loam & Sandy clay-loam \\
\hline Sand $(\%)$ & 14.8 & 61.5 \\
Silt $(\%)$ & 62.5 & 35 \\
Clay $(\%)$ & 22.8 & 3.5 \\
pH $\left(\mathrm{CaCl}_{2}\right)$ & 7.9 & 2.5 \\
TOC $(\%)$ & 1.17 & 21.40 \\
EC $\left(\mu \mathrm{Sm}^{-1}\right)$ & 220 & 141 \\
CEC $\left(\mathrm{mmol} \mathrm{kg}^{-1}\right)$ & 215.4 & 102.7 \\
\hline
\end{tabular}


prepared in $10 \mathrm{ml} \mathrm{MeOH}$ following the same soil:solvent ratio $(1: 5 \mathrm{w} / \mathrm{v})$. Three variations of the ultrasonic method were compared including (i) ultrasonic bath, as well as (ii) high and (iii) low ultrasonic energy.

The prepared samples were sonicated for 15 min for each method variation. Instead of using an ultrasonic bath, an ultrasonic probe was applied to produce 38.3 and $24.4 \mathrm{~W}$ power outputs for high and low energy ultrasonic variations, respectively. Details of each method are provided in Appendix A.

Following the same soil:solvent ratio $(1: 5 \mathrm{w} / \mathrm{v}), 2 \mathrm{~g}$ of soil sample with $10 \mathrm{ml} \mathrm{MeOH}$ was shaken overnight (min. $12 \mathrm{~h}$ ) as a modification of previously devised soil dispersion methods (Mentler et al., 2004). More details are provided in Appendix A.

For the sake of simplicity and due to the sufficient accuracy of HPLC for ecological studies (Beni et al., 2014), ergosterol was determined by chromatographic separation via $\mathrm{C} 18$ reverse phase using HPLC connected with a UV detector set at $282 \mathrm{~nm}$. The column temperature was set at $40^{\circ} \mathrm{C}$, and a mixture of $95 \% \mathrm{MeOH}$ and $5 \%$ MilliQ water was used as the mobile phase for isocratic chromatography at a flow rate of $1 \mathrm{ml} \mathrm{min}^{-1}$. The sample injection volume was $20 \mu$ l. The total retention time for ergosterol was $7.5 \mathrm{~min}$. Standard solutions were prepared containing ergosterol in $\mathrm{MeOH}$ and ranging from 3 to $50 \mu \mathrm{g} \mathrm{ml}^{-1}$. Ergosterol was calculated in $\mu \mathrm{g} \mathrm{g}^{-1}$ dry soil unit based on the extraction ratio of soil to volume as well as the dilution factor. Ergosterol yield was determined within 3 days after the extraction to avoid loss from ergosterol degradation (Beni et al., 2014).

The ergosterol yields obtained from all of the extraction methods and their variations were tested for statistically significant differences. Statistical analyses were conducted in $\mathrm{R}$ (R Core Team, 2020) with a Student t-test for the soil types and analysis of variances (ANOVA) for the extraction methods. Tukey's honestly significant difference (HSD) was employed at $\alpha=0.05$ for a multiple comparison after the ANOVA.

\section{RESULTS AND DISCUSSION}

Ergosterol yields were significantly different between soil types for all methods ( $p<0.05$ ). On average, as hypothesized, podzol contained approximately 40 -fold more ergosterol than chernozem. Ergosterol in podzol ranged from 55.63 to $124.45 \mu \mathrm{g} \mathrm{g}^{-1}$ when extracted by ultrasonic probe with low energy and alkaline methods, respectively (Fig. 1). For chernozem, the ultrasonic probe with low energy yielded the lowest ergosterol concentration $(1.55 \mu \mathrm{g}$ $\left.\mathrm{g}^{-1}\right)$ whereas the maximum value $\left(3.13 \mu \mathrm{g} \mathrm{g}^{-1}\right)$ was obtained from the miniaturized glass beads method. The higher ergosterol concentration in podzol supports the finding that soils with high organic matter and acidic $\mathrm{pH}$ are favouring fungal growth (Rousk and Bååth, 2011). Due to the higher acid tolerance and ability of fungi to degrade lignin and other recalcitrant substrates, they were more abundant in forest soil where podzolization generally occurs, particularly under pine and spruce (Nikodem et al., 2013; Bhople et al., 2019). The chernozem, on the contrary, was more alkaline $(\mathrm{pH}=7.9)$ and had a lower organic matter content, like typical meadow or agricultural soils. These conditions favour bacteria over fungi and generally result in less microbial biomass, especially if the soil structure is frequently disturbed via the tillage of agricultural soils (Ananyeva et al., 2006).

A large variation in ergosterol yields extracted using the miniaturized glass bead method from both chernozem and podzol (coefficient of variation, CV, 14.9 and $26.8 \%$, respectively) may correspond to the smallest sample size. This finding is in agreement with de Ridder-Duine et al. (2006) who noted that lowering the soil sample weight could be problematic due to small-scale variability of hyphal distribution in the soil. Hence, the small amount of soil sample (max. $2 \mathrm{~g}$ ) used in all methods supposedly contributed to variation in ergosterol yield. For podzol, the fact that a decrease in the variation of ergosterol yield from the miniaturized glass bead method was achieved by removing a potential outlier (data not shown) did not inclusively affect the pattern of extraction ability reveals its consistent

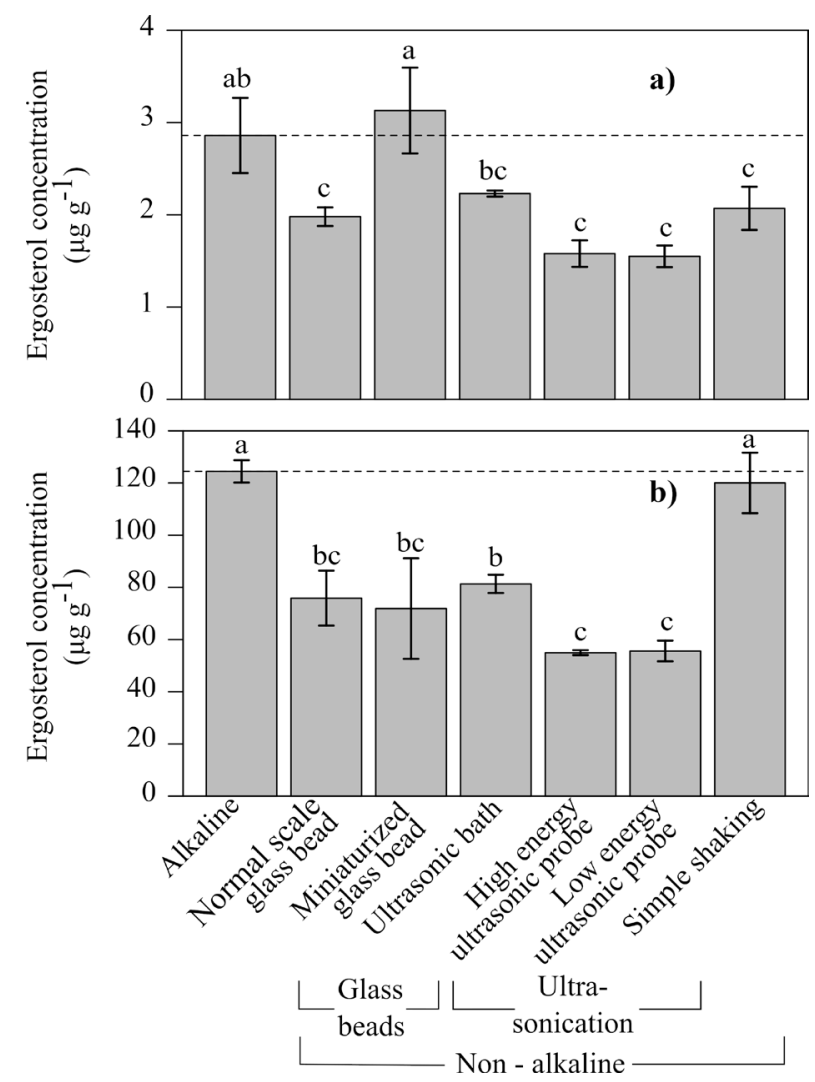

Fig. 1. Ergosterol yields extracted by different methods from a) chernozem and b) podzol soil. Bars and dashed lines represent means $\pm \mathrm{SD}(\mathrm{n}=3)$ and means from the alkaline extraction, respectively. Different letters for the extraction methods indicate significant differences at the $\mathrm{p}<0.05$. 
extraction ability. In addition to soil heterogeneity, the coextraction of other organic substances possibly increases the variation and lowers ergosterol yields for all methods through losses during the purification steps. We observed the strong interference of co-extracted organic substances particularly in the organic rich podzol (Appendix B) when extracted by alkaline and ultrasonic assisted methods.

The different ergosterol yields between methods used to test the same soil $(p<0.05$, Fig. 1) indicate that they have a different ability to extract ergosterol. Ergosterol yield from the alkaline method was amongst the highest for both soil types. This finding reveals the effect of saponification which liberated esterified ergosterol from fungal cells to maximize ergosterol yield. Surprisingly, the slightly lower ergosterol yield produced by the alkaline extraction in comparison with the miniaturized glass bead methods in chernozem suggests a potential loss of some free ergosterol during the extraction process. However, the explanation for this loss has not been found to date. Verma et al. (2002) revealed that saponification at $85^{\circ} \mathrm{C}$ for longer than $30 \mathrm{~min}$ decreased ergosterol yield. On the contrary, the effect of the loss tends to be negligible in podzol or organic rich soil. Corresponding to de Ridder-Duine et al. (2006) and Wallander et al. (2013), we suggest that the large amount of esterified ergosterol contained in organic rich soil released by saponification may compensate for the amount of decayed free ergosterol during the alkaline extraction process.

Despite findings which point towards the decay of already existing free ergosterol during the alkaline extraction process in our study and the studies by Djajakirana et al. (1996) and de Ridder-Duine et al. (2006), the lower ergosterol yields from non-alkaline extraction methods in general reveals the pitfall of physical cell disruption for ergosterol extraction. On average (excluding the miniaturized glass bead method for chernozem and the simple shaking method for podzol), the ergosterol yield for extractions using the non-alkaline methods is $78 \%$ lower than the alkaline method for podzol and $46 \%$ for chernozem. This may refer to the insufficient effectiveness of cell lysis for the protected fungal membrane by both organic substances and mineral associated aggregates. Consequently, one should be aware of systematic errors inherent to the different methods used especially when data are combined in metadata analysis.

Even though the study was limited to two soil types with an emphasis on the differences in soil type and organic matter content, only the simple shaking method showed a soil type dependency. Based on its higher extraction ability in podzol and corresponding to an improvement in soil dispersion efficiency through the addition of sand particles (Corá et al., 2009), we suggest that sand particles, which are hard and rich in podzol, may be active in cell disruption during shaking for a long period. Results from another experiment which included a greater variety of soil types revealed the soil type dependency of the simple shaking method in spite of higher ergosterol yields compared to the glass bead assisted method (Mentler, unpublished data). In addition, we recommend further studies to test the soil dependency of the methods under a wider variety of soil conditions before coming to any conclusions. The interference of co-extracted organic substances should be a concern for all methods, in particular for organic rich soil according to HPLC chromatograms (Appendix B). Extractions with glass bead assistance and simple shaking resulted in the lowest background noise in HPLC chromatograms. This suggests a high degree of ability to exclusively extract ergosterol from both soils.

For the chernozem sample, representing the organic matter poor soil, ergosterol yields extracted with glass bead assistance were comparable with those produced by the alkaline method. The miniaturized glass bead method yielded slightly more ergosterol than the alkaline method albeit not a significantly greater amount, whereas the regular scale glass bead method extracted significantly less. This implies that tube geometry as well as the setting for up- and downscaling are not completely comparable. For podzol, the ergosterol yield from the alkaline method was the highest followed by the simple shaking method, extraction with glass beads, ultrasonic bath and ultrasonic probes, respectively (Fig. 1). The assumption that non-saponification extractions only liberate free ergosterol contents may explain the lower ergosterol yield of both glass beads and ultrasonic assisted methods (Eash et al., 1996). Additionally, the required extra purification steps (such as repeated centrifugation and filtration) to diminish the coextracted organic substances lowered the ergosterol yield and may have resulted in the lowest ergosterol levels when the substance is extracted with ultrasonic probe in both soil types. Chiocchio and Matković (2011) suggested reducing the number of steps of purification to minimize ergosterol loss from the extraction procedures. Comparable ergosterol yields in podzol extracted using the alkaline method and the simple shaking extraction with the $\mathrm{MeOH}$ method suggest the advantage of mild conditioning with regard to mechanical cell lysis and extending the time spent on the co-extraction of organic compounds over intense conditioning such as beating and ultrasonication. However, the extraction ability of the simple shaking method remains unclear. For chernozem, the lowest ergosterol concentration was observed with the simple shaking extraction as shown in Fig. 1. A high degree of turbidity in the extracted solution, which leads to the requirement for more purification steps, by ultrasonic assisted methods, may be the result of the effectiveness of ultrasonication in soil dispersion (Mayer et al., 2002; Mentler et al., 2004). Therefore, the optimization of the extraction conditions for the physical cell disruption assisted methods e.g., disruption duration and energy input, will enhance extraction ability. In addition, it remains a concern that the advantage of alkaline 
extraction which produced the highest ergosterol yield in podzol was due to possibility to contain more esterified ergosterol of soil rich in organic matter (i.e. forest soil) than soil with low levels of organic matter (de Ridder-Duine et al., 2006; Wallander et al., 2013). Unlike free ergosterol, the esterified form is more stable and found in cytosolic lipid particles which are formed during their time in the stationary phase and favoured by older soil organic matter (Wallander et al., 2013). The selection of favourable ergosterol extraction methods is thus linked to a bias towards the ergosterol yield obtained.

Apart from the yield of the target substances i.e. ergosterol, other criteria such as time, cost and available equipment, chemicals and labour should be considered for method selection. In terms of ergosterol yield, the alkaline method is a good and consistent method for ergosterol extraction. Additionally, it liberates various co-extracted organic substances which can be clearly distinguished using HPLC, for both soils (Appendix Fig. 2). The extractions with glass bead assistance and simple shaking show promise with regard to lessening the interference of the co-extracted organic substances (Appendix Figs 3 and 5) in comparison with the other methods. In contrast, the co-extraction of organic substances using ultrasonication methods interferes with ergosterol determination by HPLC to a significant extent and results in a requirement for subsequent extra purification to segregate the co-extracted substances from ergosterol. The requirement for additional purification i.e. centrifugation and filtration may limit not only the ergosterol yield but also the applicability of the extraction methods due to more time consuming and the need for laboratory equipment. Furthermore, proper purification is crucial for increasing the lifetime of the HPLC column and the number of samples which may be analysed before the pre-column needs replacement. In this regard, extraction with glass bead assistance and simple shaking may be advantageous for high sample throughput without changing the HPLC column.

Despite their inability to extract esterified ergosterol, the non-alkaline extraction methods are simpler and use less hazardous chemicals in terms of both quantity and variety. $\mathrm{MeOH}$ was the only chemical used for the nonalkaline extraction in the study. In addition, ethanol (EtOH) and a mixture of $\mathrm{EtOH}$ and $\mathrm{MeOH}$ were used as the extractant for ergosterol in previous studies (Djajakirana et al., 1996; Feeney et al., 2006; Joergensen and Wichern 2008). Physical cell disruption was applied when the soil was extracted using non-alkaline methods to extensively break fungal cell membranes and subsequently maximize ergosterol yield. On the contrary, alkaline methods which are used more frequently and are well-developed for scientific research included more steps i.e. sample homogenization, saponification, phase separation, sample concentration and redissolving. Each step required hazardous chemicals and certain conditions such as methanolic alkaline solvent (such as $\mathrm{KOH}$ in $\mathrm{MeOH}$ ) for saponification reaction, cyclohexane for phase separation and $\mathrm{MeOH}$ for redissolving before measurement. An ultrasonic bath and heating were also used to accelerate its extraction process. In addition to dilution to avoid the impact of co-extracted humic substances for all extraction methods including alkaline extraction, filtration is the final step in saving the HPLC column from the interference of fine particles in the sample matrix while a HPLC analysis is carried out.

Each extraction method has benefits and limitations as shown in Table 2. None of the methods can guarantee full/complete cell lysis of fungal cells in the soil. Among them, the glass bead and the ultrasonication assisted methods were simpler and less time consuming with consistent results despite their lower extraction ability. However, they require specific materials and equipment which may not be generally available in laboratories. For glass bead assisted methods, the option to use a shaker with a prolonged disruption period when a bead-beating homogenizer is not available revealed their flexibility of operation (de RidderDuine et al., 2006) unlike ultrasonication assisted methods. The speed of the extraction apparently depends on the number of sample loads for one batch of beating or shaking and centrifugation. The homogeneity of the soil should be considered when applying miniaturized glass bead extraction. Cooling treatment is recommended to avoid the decay of the already existing ergosterol during extraction with both glass bead and ultrasonication assisted methods as used by Feeney et al. (2006) and Ruzicka et al. (2000).

The observation of turbid solutions extracted by ultrasonication assisted methods even from chernozem may be the result of inappropriate conditions either in terms of energy input, duration of energy applied or both. It probably promotes the co-extraction of organic compounds which may be more specific to the ultrasonication energy than the target substance. The optimization of these conditions will thus be necessary, before ultrasonication assisted methods can be recommended. For example, Ruzicka et al. (2000) reported that the application of an ultrasonic probe with $150 \mathrm{~W}$ for $200 \mathrm{~s}$ in association with the cooling treatment during cell lysis produced an ergosterol yield comparable with the alkaline method. The ultrasonication used here, required extra centrifugation and repeated runs of HPLC analysis due to the interference of co-extracted organic substances, making this method far less time efficient than anticipated. The most favourable ultrasonication extraction in this study was the ultrasonic bath; however, this method has the shortcoming that the energy input is impossible to monitor for single samples and hence questions concerning reproducibility arise in the case of large number of samples.

Despite a higher degree of extraction ability, the alkaline method is the most demanding method. This includes time, the variety of chemicals, skills, equipment as well as glassware. Due to its chemical and glassware consumption, it produced both a greater quantity and more hazardous 
Table 2. Advantages and comments for ergosterol extraction methods

\begin{tabular}{|c|c|}
\hline Advantages & Comments \\
\hline \multicolumn{2}{|r|}{ Alkaline } \\
\hline $\begin{array}{l}\text { - Liberation of free and esterified } \\
\text { ergosterol from fungal cells } \\
\text { - Well-established and widely used in } \\
\text { scientific community } \\
\text { - Low amount of soil sample }(1 \mathrm{~g}) \\
\text { - High reproducibility, and scalability }\end{array}$ & $\begin{array}{l}\text { - Potential for partial cell lysis phenomenon } \\
\text { - Decay of some already existing free ergosterol during extraction } \\
\text { - Time and chemical consumption subsequently larger amount of hazardous waste } \\
\text { - Specific equipment and skilled or trained labor requirement } \\
\text { - Glassware supply and cleaning step essentials } \\
\text { - Interference from organic substances in organic-rich soil }\end{array}$ \\
\hline \multicolumn{2}{|r|}{ Non-alkaline } \\
\hline \multicolumn{2}{|r|}{ Glass beads } \\
\hline $\begin{array}{l}\text { - Simple and the least time consuming } \\
\text { - High throughput } \\
\text { - Less co-extraction of organic substances } \\
\text { - Less chemical use } \\
\text { - High reproducibility } \\
\text { - Minimum amount of soil sample (for } \\
\text { miniaturized glass bead method) } \\
\text { - Options between beating and shaking }\end{array}$ & $\begin{array}{l}\text { - Potential for partial cell lysis phenomenon and inability to liberate esterified } \\
\text { ergosterol } \\
\text { - Decay of some already existing free ergosterol by heat generated during cell } \\
\text { disruption } \\
\text { - Specific materials (glass beads) and equipment (e.g. bead-based homogenizer) } \\
\text { requirement } \\
\text { - Interference from organic substances in organic-rich soil } \\
\text { - Minimum extracted volume of miniaturized glass beads method }\end{array}$ \\
\hline \multicolumn{2}{|r|}{ Ultrasonication } \\
\hline $\begin{array}{l}\text { - Simple and moderate time consuming } \\
\text { - Less chemical use } \\
\text { - High reproducibility }\end{array}$ & $\begin{array}{l}\text { - Potential for partial cell lysis phenomenon and inability to liberate esterified } \\
\text { ergosterol } \\
\text { - Decay of some already existing free ergosterol by heat generated during cell } \\
\text { disruption } \\
\text { - Above resulting in low yield } \\
\text { - Specific equipment (e.g. ultrasonic bath or probe) requirement } \\
\text { - Interference from organic substances in organic-rich soil } \\
\text { - Optimization of extraction condition needed, to avoid over disruption of soil } \\
\text { particles and co-extraction of organic substances }\end{array}$ \\
\hline \multicolumn{2}{|r|}{ Simple shaking } \\
\hline $\begin{array}{l}\text { - The least demanding method nearly } \\
\text { without specific equipment need } \\
\text { - High throughput } \\
\text { - Less co-extraction of organic substances } \\
\text { - Mild condition extraction }\end{array}$ & $\begin{array}{l}\text { - Potential for partial cell lysis phenomenon and inability to liberate esterified ergosterol } \\
\text { - Interference from organic substances in organic-rich soil } \\
\text { - Tending to be soil dependent }\end{array}$ \\
\hline
\end{tabular}

waste for disposal than the other methods. The simple shaking method is the simplest method, but the results from the extraction do not provide sufficient evidence, even though it showed comparable results with the alkaline method for podzol. Less demanding in terms of labour, chemicals and the specific equipment required, the simple shaking method shows a high degree of potential for application in a large number of laboratories. In addition, the fact that all podzol samples required more centrifugation and dilution regardless of the method used implies the significant effect of organic matter considering the subsequently co-extracted organic substances on purity of the extracted solution. Therefore, further purification steps should be considered in future studies for all methods particularly with regard to avoiding interference from co-extracted organic substances in soil rich in organic matter.

\section{CONCLUSIONS}

1. Regardless of the methods used, ergosterol yield in podzol was higher than in chernozem. Among them, the alkaline method had the greatest extraction ability, whereas the glass bead-assisted and ultrasonic bath methods were comparable. Despite the limit of soil types in the study, our results only presented the soil type dependence of the simple shaking method.

2. The co-extraction of organic substances was observed with all tested methods, but less pronounced when they were extracted by the glass bead assisted and the simple shaking method.

3. In terms of applicability, the non-alkaline extraction methods were simple and used less hazardous chemicals than the alkaline method. However, the required materials and equipment of the non-alkaline methods are often either difficult to obtain or not available for all laboratories. 
4. Based on our results, we suggest the use of the miniaturized glass bead method for ergosterol extraction from agricultural soils with a large number of samples if no significant interference of co-extractants is expected e.g. for the purposes of comparing soil tillage management in agricultural soils even though, all of the methods lacked a proper clean-up step meant to prevent the co-extraction of organic substances.

\section{ACKNOWLEDGEMENTS}

We are grateful to Maximilian Prokop, Elisabeth Kopecky, Astrid Hobel and Karin Hackl for their support during the laboratory work.

Conflict of interest: The authors declare no conflict of interest.

\section{REFERENCES}

Ananyeva N.D., Susyan E. A., Chernova O.V., Chernov I.Yu., and Makarova O.L., 2006. The ratio of fungi and bacteria in the biomass of different types of soil determined by selective inhibition. Microbiology, 75, 702-107. https://doi. org/10.1134/s0026261706060130

Bååth E. and Anderson T.H., 2003. Comparison of soil fungal/ bacterial ratios in a ph gradient using physiological and PLFA-Based Techniques. Soil Biol. Biochem., 35, 955-963. https://doi.org/10.1016/s0038-0717(03)00154-8

Bååth E., 2001. Estimation of fungal growth rates in soil using 14C-Acetate Incorporation into ergosterol. Soil Biol. Biochem., 33, 2011-2018. https://doi.org/10.1016/s0038-0717(01)00137-7

Beni A., Soki E., Lajtha K., and Fekete I., 2014. An Optimized HPLC method for soil fungal biomass determination and its application to a detritus manipulation study. J. Microbiol. Methods, 103, 124-130. https://doi.org/10.1016/j.mimet.2014.05.022

Bhople P., Djukic I., Keiblinger K., Zehetner F., Liu D., Bierbaumer M., Zechmeister-Boltenstern S., Joergensen R.G., and Murugan R., 2019. Variations in soil and microbial biomass $\mathrm{C}, \mathrm{N}$ and fungal biomass ergosterol along elevation and depth gradients in alpine ecosystems. Geoderma, 345, 93-103.

https://doi.org/10.1016/j.geoderma.2019.03.022

Chiocchio V.M. and Matković L., 2011. Determination of ergosterol in cellular fungi by HPLC. A modified technique. J. Argentine Chemical Society, 98, 10-15.

Corá J.E., Fernandes C., Beraldo J.M.G., and Marcelo A.V.M., 2009. Use of sand for soil dispersion in granulometric analysis. Revista Brasileira de Ciência do Solo, 33, 255-262. https://doi.org/10.1590/s0100-06832009000200003

Djajakirana G., Joergensen R.G., and Meyer B., 1996. Ergosterol and microbial biomass relationship in soil. Biology Fertility of Soils, 22, 299-304. https://doi.org/10.1007/s003740050115

Eash N.S., Stahl P.D., Parkin T.B., and Karlen D.L., 1996. A simplified method for extraction of ergosterol from Soil. Soil Science Society of America J., 60, 468-471. https://doi. org/10.2136/sssaj1996.03615995006000020018x
Feeney D.S., Crawford J.W., Daniell T., Hallett P.D., Nunan N., Ritz K., Rivers M., and Young I.M., 2006. Threedimensional microorganization of the soil-root-microbe system. Microbial Ecology, 52, 151-158.

https://doi.org/10.1007/s00248-006-9062-8

Gong P., Guan X., and Witter E., 2001. A rapid method to extract ergosterol from soil by physical disruption. Applied Soil Ecology, 17, 285-89.

https://doi.org/10.1016/s0929-1393(01)00141-x

van Groenigen K.J., Bloem J., Bååth E., Boeckx P., Rousk J., Bodé S., Forristal D., and Jones M.B., 2010. Abundance, production and stabilization of microbial biomass under conventional and reduced tillage. Soil Biol. Biochem., 42, 48-55. https://doi.org/10.1016/j.soilbio.2009.09.023

Joergensen R.G. and Wichern F., 2008. Quantitative assessment of the fungal contribution to microbial tissue in soil. Soil Biol. Biochem., 40, 2977-2991. https://doi.org/10.1016/j. soilbio.2008.08.017

Mayer H., Mentler A., Papakyriacou M., Rampazzo N., Marxer Y., and Blum W.E.H., 2002. Influence of vibration amplitude on the ultrasonic dispersion of soils. Int. Agrophysics, 16, 53-60.

Mentler A., Mayer H., Strauß P., and Blum W.E.H., 2004. Characterisation of soil aggregate stability by ultrasonic dispersion. Int. Agrophysics, 18, 39-45.

Newell S.Y., Arsuffi T.L., and Fallon R.D., 1988. Fundamental procedures for determining ergosterol content of decaying plant material by liquid chromatography. Applied Environ. Microbiol., 54, 1876-1879.

https://doi.org/10.1128/aem.54.7.1876-1879.1988

Nikodem A., Pavlů L., Kodešová R., Borůvka L., and Drábek O., 2013. Study of podzolization process under different vegetation cover in the Jizerské hory Mts. Region. Soil Water Res., 8, 1-12. https://doi.org/10.17221/56/2012-swr

de Ridder-Duine A.S., Smant W., van der Wal A., van Veen J.A., and de Boer W., 2006. Evaluation of a simple, non-alkaline extraction protocol to quantify soil ergosterol. Pedobiologia, 50, 293-300. https://doi.org/10.1016/j.pedobi.2006.03.004

R Core Team, 2020. R: A language and environment for statistical computing. R Foundation for Statistical Computing, Vienna, Austria. URL https://www.R-project.org/.

Rousk J. and Bååth E., 2011. Growth of saprotrophic fungi and bacteria in soil. FEMS Microbiol. Ecology, 78, 17-30. https://doi.org/10.1111/j.1574-6941.2011.01106.x

Ruzicka S., Norman M.D.P., and Harris J.A., 1995. Rapid ultrasonication method to determine ergosterol concentration in soil. Soil Biol. Biochem., 27, 1215-1217. https://doi. org/10.1016/0038-0717(95)00039-h

Ruzicka S., Edgerton D., Norman M., and Hill T., 2000. The utility of ergosterol as a bioindicator of fungi in temperate soils. Soil Biol. Biochem., 32, 989-1005.

https://doi.org/10.1016/s0038-0717(00)00009-2

Schomakers J., Zehetner F., Mentler A., Ottner F., and Mayer H., 2015. Study of soil aggregate breakdown dynamics under low dispersive ultrasonic energies with sedimentation and X-ray attenuation. Int. Agrophys., 29, 501-508. https://doi. org/10.1515/intag-2015-0057

Seitz L.M., Mohr H.E., Burroughs R., and Sauer D.B., 1977. Ergosterol as an indicator of fungal invasion in grains. Cereal Chemistry, 54, 1207-1217. 
Strickland M.S. and Rousk J., 2010. Considering fungal: bacterial dominance in soils - methods, controls, and ecosystem implications. Soil Biol. Biochem., 42, 1385-1395. https://doi.org/10.1016/j.soilbio.2010.05.007

Turgay O.C. and Nonaka M., 2002. Effects of land-use and management practices on soil ergosterol content in andosols. Soil Sci. Plant Nutrition, 48, 693-99. https://doi.org/1 0.1080/00380768.2002.10409259

Verma B., Robarts R.D., Headley J.V., Peru K.M., and Christofi N., 2002. Extraction efficiencies and determination of ergosterol in a variety of environmental matrices. Communications in Soil Science and Plant Analysis, 33, 3261-3275. https://doi.org/10.1081/css-120014521

Wallander H., Ekblad A., Godbold D.L., Johnson D., Bahr A., Baldrian P., Björk R.G., Kieliszewska-Rokicka B., Kjøller
R., Kraigher H., Plassard C., and Rudawska M., 2013. Evaluation of methods to estimate production, biomass and turnover of ectomycorrhizal mycelium in forests soils - A Review. Soil Biol. Biochem., 57, 1034-1047. https://doi.org/10.1016/j.soilbio.2012.08.027

Young I.M., Illian J., Harris J.A., and Ritz K., 2006. Comment on Zhao et al. (2005) Does ergosterol concentration provide a reliable estimate of soil fungal biomass? Soil Biol. Biochem., 38, 1500-1501.

https://doi.org/10.1016/j.soilbio.2005.10.021

Zhao X.R., Lin Q., and Brookes P.C., 2005. Does soil ergosterol concentration provide a reliable estimate of soil fungal biomass? Soil Biol. Biochem., 37, 311-317. https://doi.org/10.1016/j.soilbio.2004.07.041 